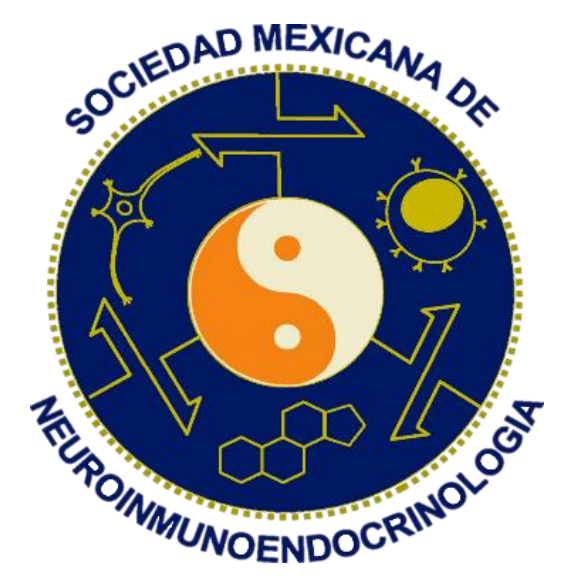

\title{
Simposio: Enfermedades mentales.
}

\section{Congreso de la Sociedad Mexicana de Neuroinmunoendocrinología.}

Puerto Vallarta Jalisco, México. 21 al 24 de Octubre del 2019.

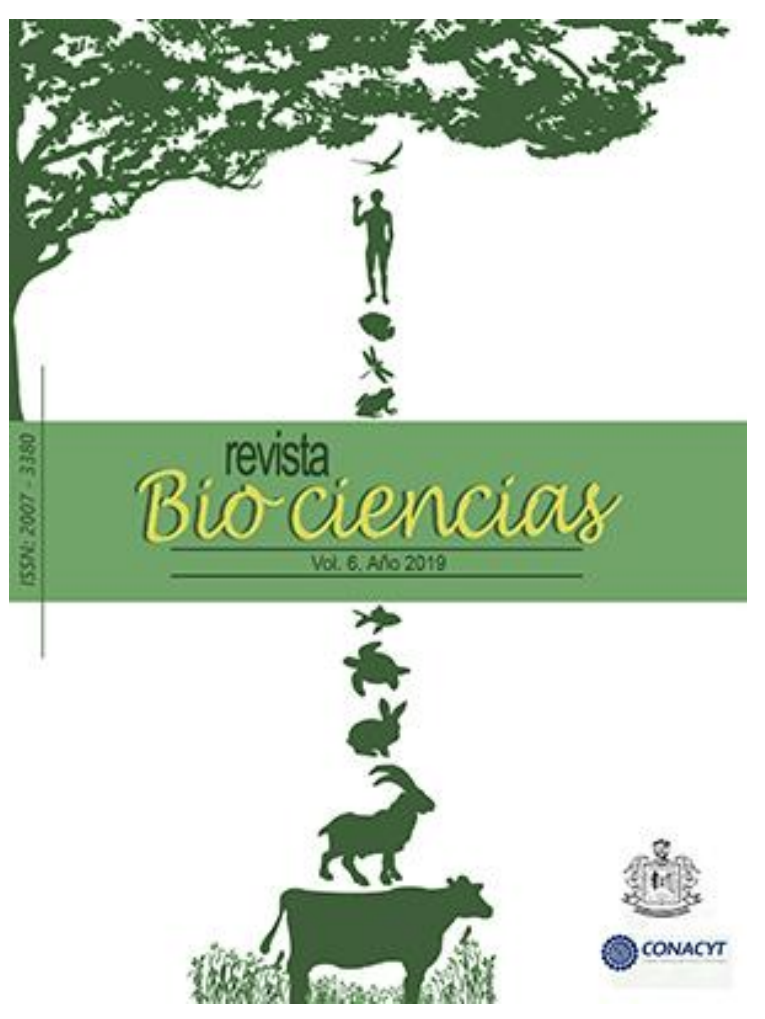




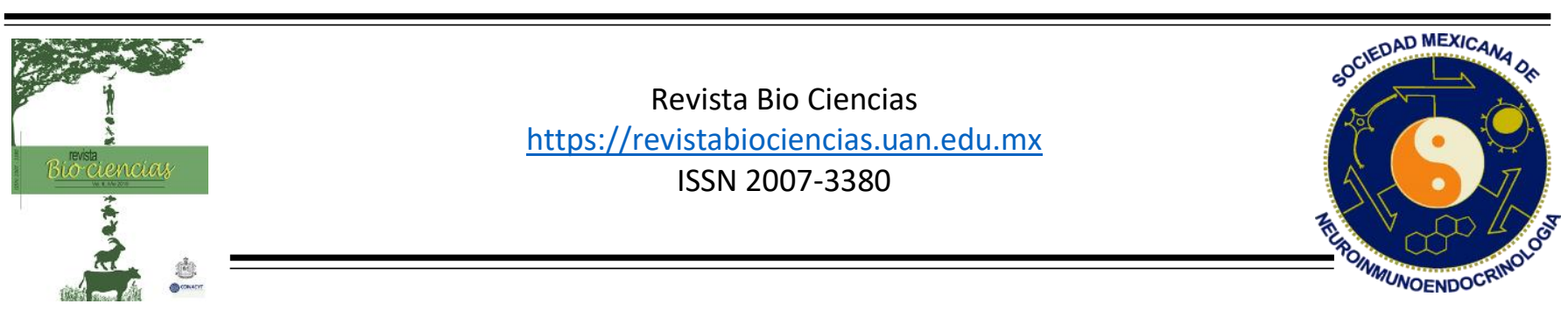

Simposio: Enfermedades mentales

\title{
Expresión de receptores dopaminérgicos y serotoninérgicos de pacientes con esquizofrenia tratados con risperidona
}

\begin{abstract}
Álvarez Herrera S.
3Instituto Nacional de Psiquiatría "Ramón de la Fuente Muñiz", Laboratorio de Psicoinmunología. Calzada México Xochimilco No. 101, Colonia San Lorenzo Huipulco, Delegación Tlalpan, México DF.

La participación de la respuesta inflamatoria en la fisiopatología de la esquizofrenia es cada vez más evidente; la presencia de un estado inflamatorio en los pacientes durante los episodios psicóticos agudos, así como el efecto anti-inflamatorio de los antipsicóticos atípicos (APAs) apoyan la vertiente de una comunicación bidireccional alterada entre los sistemas Nervioso Central (SNC) e Inmunológico (SI). A pesar de la gran cantidad de estudios que muestran alteraciones en marcadores inflamatorios, aun no existe un marcador biológico de utilidad clínica para el diagnóstico o el seguimiento clínico de los pacientes.

Las células mononucleares de sangre periférica (CMSP) se han utilizado como modelo por su facilidad de obtención, para el estudio y búsqueda de alteraciones

fenotípicas y funcionales que reflejen alteraciones en SNC. En esquizofrenia, se han demostrado cambios en activación celular, expresión de receptores y liberación de citocinas asociadas a la enfermedad y al tratamiento farmacológico que consumen los pacientes. Los APAs antagonizan receptores en SNC al igual que en células periféricas que los expresen como las CMSP; es por esto que estos fármacos pueden ejercer un efecto funcional en estas células que alteran la respuesta inmunológica sistémica. Los resultados preliminares de esta investigación muestran los cambios en la expresión de receptores de dopamina y serotonina en CMSP de pacientes con esquizofrenia en episodio psicótico agudo y los cambios en dicha expresión por el consumo del antipsicótico atípico risperidona.
\end{abstract}

Cite this paper/Como citar este artículo: Álvarez S. (2019). Expresión de receptores dopaminérgicos y serotoninérgicos de pacientes con esquizofrenia tratados con risperidona. Revista Bio Ciencias 6: (Suppl) Memorias IV Congreso de la Sociedada Mexicana de Neuroinmunoendocrinología. e841. http://doi.org/10.15741/revbio.06.Suppl.e853 